Int. J. Electrochem. Sci., 12 (2017) $4056-4076$

\title{
Effect of Calixarene Sulfonic Acids Hydration on Their Proton Transport Properties
}

\author{
Lyubov Shmygleva ${ }^{1, *}$, Nikita Slesarenko ${ }^{l}$, Aleksander Chernyak ${ }^{1,2}$, Evgeny Sanginov ${ }^{1}$, \\ Aleksander Karelin ${ }^{l}$, Anna Pisareva ${ }^{1}$, Rostislav Pisarev ${ }^{1}$, Yury Dobrovolsky ${ }^{1}$ \\ ${ }^{1}$ Institute of Problems of Chemical Physics of RAS, 1 Academician Semenov Avenue, \\ Chernogolovka, Moscow region, Chernogolovka, Russia, 142432 \\ ${ }^{2}$ Science Center in Chernogolovka RAS, 9 Lesnaya str., Chernogolovka Moscow Region, 142432 \\ *E-mail: shmygleval@mail.ru
}

doi: $10.20964 / 2017.05 .47$

Received: 18 November 2016 / Accepted: 19 January 2017 / Published: 12 April 2017

The influence of the morphology of calix(n)arene sulfonic acid hydrates with different number of aromatic rings $(n=4,6,8)$ on their proton transport properties was studied. Simultaneous thermal analysis, IR spectroscopy, X-ray powder diffraction and nuclear magnetic resonance were used for investigating of proton hydrate shell, water content and structure features. It was shown that studied calix(n)arene sulfonic acids hydrates have high proton conductivity up to $10^{-1} \mathrm{~S} / \mathrm{cm}$.

Keywords: Calixarene sulfonic acids, water content, proton conductivity, activation energy, NMR study.

\section{FULL TEXT}

(C) 2017 The Authors. Published by ESG (www.electrochemsci.org). This article is an open access article distributed under the terms and conditions of the Creative Commons Attribution license (http://creativecommons.org/licenses/by/4.0/). 